\title{
ASSESSMENT OF GENETIC DIVERSITY IN TAMARIND (Tamarindus indica L. ) USING RANDOM AMPLIFIED POLYMORPHIC DNA MARKERS
}

\author{
M. Kumar*, V. Ponnuswami, C. Rajamanickam and. T.L. Preethi \\ Horticultural College and Research Institute, Periyakulam, Tamil Nadu, India-625604
}

\begin{abstract}
Determination of genetic variation is important to the plant breeders for development of high yielding variety. The aim of the current study was to investigate the genetic diversity of nine tamarind cultivars, out of nine four flowering cultivars using random amplified polymorphic DNA (RAPD) markers. Ten Random amplified polymorphic DNA (RAPD) primers were used to assess the genetic diversity in four flowering cultivars and five non-flowering of tamarind trees. The average genetic similarity level among the four flowering cultivars and five non-flowering accessions grouped into six clusters groups at $0.76 \%$. RAPD profiles of all the tamarind were compared and a total of 58 scorable bands were produced with seven primers ranging from one for OPG-13 to twelve for OPA-R15. Genotypes which were morphological closely related were found to be unrelated at the molecular level. A sizeable amount of intrapopulation diversity recorded in the present study which can be utilized in hybridization programmes to efficiently introgress the desirable trait of interest.
\end{abstract}

Keywords: Cultivars, Diversity, RAPD, Tamarind

\section{INTRODUCTION}

Tamarind (Tamaridus indica L.) is a dicotyledonous perennial tree belongs to the family Fabaceae (Leguminaceae) and sub family Caesalpinioideae. It is a diploid species with a chromosome number $2 \mathrm{n}=26$ (Purseglove, 1987). The species has a wide geographical distribution in the subtropics and semiarid tropics and is cultivated in numerous regions. It is mostly self sown or sown with seeds of unknown parentage, which result in wide variation among seedling progenies. Owing to its wide geographical distribution and adaptability to different agro climatic zones, large genetic diversity is present in the seedling population. Due to cross pollination and predomination of seed propagation over a large period of time, it gives immense opportunity to locate elite trees having desirable horticultural traits (EL-Siddig,

*Corresponding author email: kumarhorti@yahoo.com

Received: 21.04.2014 
2006). Recent investigation was carried out to find out the variability on the basis of growth parameters of different seedling progenies so that valuable germplasm could be protected from being eroded and at the same time their utilization is also maximized under crop improvement (Gunasena et al., 2000).

Tamarindus itself is a monotypic genus, containing the sole species T. indicus. Being a highly cross-pollinated crop, wide variability is common in this species. Such an individual variation between the trees within a population is of paramount importance and it may be worthwhile in selecting the very best trees in relation to neighboring ones within ecological zones for increasing their frequencies. The present study is an effort to examine the extent of genetic diversity and assess genetic relationships among tamarind cultivars using DNA markers.

\section{MATERIALS AND METHODS}

\section{Plant material}

Tamarind widely grown in different parts of India, have been collected and maintained at the Horticultural College and Research Institute, Periyakulam. Nine cultivars from this collection were used in this study (Table 1).

\section{DNA extraction}

Total genomic DNA was isolated from tamarind leaves were collected from the field and washed thoroughly using distilled water: $0.5 \mathrm{~g}$ of leaf tissue was used for DNA extraction. DNA was extracted following the (CTAB) extraction method. Leaf tissue was ground to a fine powder using a pestle and mortar with liquid nitrogen, and $6 \mathrm{ml}$ of extraction buffer $(2 \% \mathrm{w} / \mathrm{v} \mathrm{CTAB}, 1.4 \mathrm{M} \mathrm{NaCl}, 20 \mathrm{mM}$ EDTA, $0.1 \%$ ßmercaptoethanol, $100 \mathrm{mM}$ Tris $\mathrm{pH} 8.0$ ), preheated to $60^{\circ} \mathrm{C}$, was added to the ground leaves and mixed and transferred to centrifuge tubes. Following the addition of 50 mg PVPP (polyvinylpolypyrrolidone), the tubes were inverted 2-3 times to ensure thorough mixing. The centrifuge tubes were incubated at $60^{\circ} \mathrm{C}$ for $1 \mathrm{~h}$ with occasional shaking, and cooled to room temperature. Then $8 \mathrm{ml}$ of $24: 1$ chloroform:isoamylalcohol was added and mixed gently by inverting the tubes 20-25 times to form an emulsion and centrifuged at $8,000 \mathrm{~g}$ for $5 \mathrm{~min}$ at room temperature. The clear aqueous phase was then transferred to fresh tubes and $1 \mathrm{ml}$ of $5 \mathrm{M} \mathrm{NaCl}$ was added. After the addition of $8 \mathrm{ml}$ isopropanol, the tubes were incubated at $-20^{\circ} \mathrm{C}$ overnight. The contents of the tubes were centrifuged at 12,000 rpm for $20 \mathrm{~min}$, the supernatant was discarded, and the pellet was washed twice with cold $70 \%$ ethanol. The DNA pellet was dried at $37^{\circ} \mathrm{C}$ for 30 minutes. The dried DNA pellet was dissolved in $1 \mathrm{ml}$ of Tris-EDTA ( $\mathrm{pH}$ 8.0) buffer containing RNAase $\left(20 \mu \mathrm{g} \mathrm{ml}^{-1}\right)$ and incubated at $37^{\circ} \mathrm{C}$ for $1 \mathrm{~h}$. The physical integrity of the DNA was verified by agarose gel electrophoresis $(0.8 \%)$ and the DNA content was quantified by measuring OD at $260 \mathrm{~nm}$. 


\section{PCR and RAPD analysis}

Tamarind DNA was amplified by polymerase chain reaction (PCR) as described by Williams et al. (1990). The PCR reaction was carried out in $20 \mu \mathrm{l}$ reaction mixture containing $100 \mathrm{ng}$ template DNA, $0.3 \mu \mathrm{M}$ primer, $2.6 \mathrm{mM} \mathrm{MgCl} 2$, 0.5 units of taq polymerase, and $100 \mathrm{mM}$ of each dNTPs. PCR cycles included initial denaturation at $93^{\circ} \mathrm{C}$ for $3 \mathrm{~min}$ followed by 40 cycles of $2 \mathrm{sec}$ denaturation at $92^{\circ} \mathrm{C}, 2$ sec annealing at $35^{\circ} \mathrm{C}$ and $1 \mathrm{~min} 30 \mathrm{sec}$ polymerization at $72^{\circ} \mathrm{C}$. Finally, extended polymerization at $72^{\circ} \mathrm{C}$ was done for $8 \mathrm{~min}$. Amplified products were separated on a $1.5 \%$ agarose gel containing ethidium bromide $\left(0.5 \mu \mathrm{g} \mathrm{ml}^{-1}\right)$. Electrophoresis was carried out for $2-2.5 \mathrm{~h}(5 \mathrm{~V} / \mathrm{cm})$. Later the gel was visualized under UV light and photographed. Using pooled DNA from all cultivars. The presence of a RAPD band in each position was recorded as 1 and its absence as 0. RAPD bands for each primer were scored separately. Using these data, squared Euclidian distances were calculated to estimate all pair-wise differences in the RAPD markers for all cultivars (Sokal and Sneath 1973). Ten primers (OPA-A09, OPA-B06,OPA-K06,OPA-R15,OPAX01,OPA-Y01,OPG-19,OPG-05,OPG-13 and OPG-09 were screened to identify suitable primers for RAPD analysis. From them, seven primers (OPA-A09, OPAB06, OPA-K06, OPA-R15, OPA-X01, OPA-Y01, and OPG-19) were able to detect distinct, clearly resolved and polymorphic amplified products (Table 2).

\section{Scoring of bands and statistical analysis}

Amplified bands were scored present (1) or absent (0) regardless of band intensities. Ambiguous data scored as missing data. The scored band data was subjected to statistical analysis using the computer programme 'STATISTICA'. The agglomerative method of clustering using Ward's method (Ward, 1963) for developing dendrogram was adopted. A distance matrix was also worked out based on dissimilarity measure Squared Euclidean Distances (SED).

\section{RESULTS}

Random amplified polymorphic DNA (RAPD) analysis carried out on all the accessions produced a large number of distinct fragments for each primer. Genetic diversity based on RAPD studies of the ten primers used to screen RAPD diversity of $T$. indica cultivars; seven primers were found to produce distinct polymorphic bands. A total of 58 polymorphic amplification fragments were generated across the whole sample Table. 2, lists the polymorphic primers, their sequences and the number of polymorphic markers found in the four cultivars and five accessions. The number of bands produced per primer varied from 5-12. Among the selected primers OPA-R15 produced maximum number of bands (12 bands) and minimum of 1 bands produced by the primer OPG-13. Primer OPA-B06 amplified a unique fragment of $150 \mathrm{bp}$ specific to genotype of PKM1, Red tamarind and Sweet tamarind (Figure 2). We obtained moderate degree of genetic diversity, with Jaccard's similarity co-efficient values ranging from urigam and $T I-9$ had $100 \%$ similarity there is no variation, 
cluster I and II had maximum variation 51\% with accessions of TI-3 and TI-7. PKM1 and Red tamarind cultivars had $87.5 \%$ similarity; Sweet tamarind had $85.5 \%$ similarity with PKM1 and Red tamarind. $T I-1$ had a 54.55 similarity with $T I-2$. This is the first report in India describing the genetic diversity in tamarind using DNA markers. Tamarind was found to have genetic heterozygosity and level of polymorphism observed in present study. Indicating that a wide and diverse genetic base existed between genotypes of tamarind. This variation may be due to the diverse genotypes used and partly due to its cross pollinating nature. The variation between genotypes observed with 9 of the 10 selected primers, can be used for identification of superior type and also for genotype specific DNA markers. The 10 primers showing repeated amplification and the 58 were polymormphic indicating considerable genetic variation among the tamarind genotypes.

In the present study, dendrogram generated from the Unweighted pair group arithmetic average (UPGMA) cluster analysis broadly placed 9 tamarind cultivars in to six major cluster at co-efficient of $0.76 \%$ (Figure 1). The cluster size varied from 1 to 6 and cluster VI was the largest cluster comprising of three cultivars followed by cluster V possessing 2 and cluster IV, III, II and I possessing one varieties. The cluster VI the most diverse cultivars namely, PKM1, Red tamarind and Sweet tamarind. The cluster $\mathrm{V}$ which included cultivars of $T I-9$ and Urigam. The cluster I, II, III and IV falling only one TI-3,TI-7, TI-1 and TI-2.

\section{DISCUSSION}

This is the first report in India describing the genetic diversity in tamarind using DNA markers. RAPD has been successfully used to study the genetic diversity in trees viz., eucalyptus (Keil \& Griffin, 1994), mango (Ravishankar et al., 2000) and plum (Shimida et al. 1999), teak (Keiding et al., 1986) and oil palm (Shah et al., 1994). RAPD markers proved to be very informative and useful in monitoring the genetic diversity present in samples of selected genotypes. Tamarind was found to have genetic heterozygosity of 0.15 and the level of polymorphism observed in present study was fairly high (0.76) indicating that a wide and diverse genetic base existed between genotypes of tamarind. This variation may be due to the diverse genotypes used and partly due to its cross pollinating nature. Similar discriminative ability of RAPD markers in identifying the genotypes has been documented in several other fruit crops like avocado (Lewis 1992), apple (Koller et al., 1993), mango (Schnell et al.,1995; Hemanthkumar et al., 2000), guava (Prakash et al., 2002).RAPD has been successfully used to study the genetic diversity in tree viz., eucalyptus (Keil Griffin, 1994), Mango (Ravishankar et al., 2000) and Plum (Shimida et al., 1999), Teak (Keiding et al., 1986) and oil palm (Shah et al., 1994). RAPD markers proved to be very informative and useful in monitoring the genetic diversity present in sample of selected genotypes. The result in coffee by Laslermes et al., (1993) showed the ability of RAPD to discriminate among genotypes and suggested their application in cultivar identification. The similar results high similarity 
coefficient value of 0.82 was found between two cultivars of sweet oranges, similar to the result obtained by previous studies (0.82-0.88) done by Gulsen and Roose (2001), among 95 citrus accessions and for ISSR, SSR and isozymes analysis. Nine of 25 primers used were not able to differentiate and gave monomorphic bands. The high similarity $(0.82)$ between the 2 cultivars of sweet oranges is probably due to their common origin by mutation (Elisiario et al., 1999). The similar results, twentyfive primers produced 219 alleles among 5 genotypes of lime and lemon group, of which 138 were polymorphic. Between 4 and 10 clear and repeatable bands were obtained for each of these primers, which is similar to the results (1 to 9 alleles) obtained by Abkenar and Isshiki (2003) in 31 acid citrus species and cultivars. A search for unique bands was made for all the species tested and it was found that primers OPO-17 and OPB-14 gave 2 and 3 unique bands respectively for Jatti-Khatti genotype. Nicolosi et al. (2000) also reported 2 unique bands in C. limonia and 1 unique band in $C$. aurantium in a study on phylogeny and genetic origin of Citrus. In a similar study carried for the assessment of genetic diversity in 57 Musa genotypes at NBPGR, New Delhi, Bhat and Jarret 1995, reported that 49 promising primers yielded 605 scorable bands with an average of 12.35 bands per primers in a similar study. High level of genetic diversity in acid lime varieties has been reported by previous studies and composed of different phenotype, genotype and large number of varieties. This variation allows identifying the different cultivars with molecular markers. Molecular marker may provide information on the history and biology of cultivars, but it does not necessary to reflect what may be observed in morphological traits (Metais et al., 2000). Wide variation was observed among the different genotypes with respect to growth and yield traits and this may be attributed to their genotypic differences. In addition, age of the tree is also an important factor which influences the yield. Kadam et al. (2005) reported that yield increased in sapota trees up to 30 years of age. Attempts have been made to evaluate the sapota germplasm for different agronomic traits. These studies indicated great variation in fruit size, production and quality of fruits (Chundawat and Bhuva, 1982; Rokhade et al., 1989). Chundawat and Bhuva (1982) evaluated the performance of five sapota cultivars and found Kalipatti to be the best in terms of yield and quality. Though RAPD markers proved to be useful for germplasm characterization and diversity analysis in citrus in the present study, use of other molecular marker techniques such as AFLP, ISSR and SSRs should be considered for finer molecular analysis of genotypes and to solve discrepancies left unresolved by RAPDs.

\section{CONCLUSION}

This will also help in choosing the core collection which represents the genetic spectrum of the entire collection. The identified plus trees having a higher pulp weight to seed weight ratio can thus be suggested for clonal propagation. Thus, from the studies it can be concluded that tamarind is an economically important multipurpose tree species. With the increasing population pressure, the demand for 
tamarind pulp has increased considerably. This has necessitated identifying superior elite trees like genotypes for monoculture plantations, without causing genetic erosion. Thus tree improvement through the application of genetic principles is basically directed towards modifying the heredity of tree populations to meet the needs of the farmers.

\section{REFERENCES}

Abkenar, A. and Isshiki. S. 2003. Molecular characterization and genetic diversity among Japanese acid citrus (Citrus spp.) based on RAPD markers. Journal of Horticultural Sciences and Biotechnology, 78: 553-556

Bhat, K.V. and Jarret, R.L. 1995. Random amplified polymorphic DNA and genetic diversity in Indian musa germplasm. Genet. Resour. Crop Evaluation, 42: 107 - 118

Chundawat BS and Bhuva., H.P.1982. Performance of some cultivars of sapota (Archas sapota L.) in Gujarat. Haryana Journal of Horticultural Sciences, 11: 154-158

Elisiario, P.J., E.M. Justo and J.M. Leitao. 1999. Identification of mandarin hybrids by isozyme and RAPD analysis. Scientia Horticutlurae, 81: 287-99

El-Siddig, Gunasena.B. 2006. Tamarind, Tamarindus indica. Southampton Centre for underutilized crops, Southampton, UK.

Gulsen, O. and Roose, M.L. 2001. Lemons diversity and relationship with selected citrus genotypes as measured with nuclear genome marker. Journal of the American Society for Horticultural Science, 126: 309-317

Hemanthkumar N.V, Narayanaswamy, P., Prasad, T.G., Mukunda, G.K and S.N .Sondur. S.N. 2001. Estimation of genetic diversity of commercial mango (Mangifera indica L.) cultivars using RAPD markers. Journal of Horticultural Science and Biotechnology, 76: $529-533$

Nicolosi, E., Deng, Z.N., Gentile, A.C.A.,Malfa, Continella, S.G and Tribulato, E. 2000. Citrus phylogeny and genetic origin of important species as investigated by molecular markers. Theoretical Applied Genetics, 100: 1155-66

Kadam D.D, Jadhav, Y.R., and Patgaonkar, D.R 2005. Linear relationship between yield and number of fruits of sapota and sweet orange trees. South Indian Horticulture, 53: 15-17

Keiding H, Wellendorf, H., and Lauridsen, E.B 1986, In: Evaluation of international series of teak provenance trials. DANIDA Forest seed center, Humleback, Denmark, pp.81

Keil. M and Griffin, A.R. 1994 Use of random amplified polymorphic DNA (RAPD) markers in the discrimination and verification of genotypes in Eucalyptus. Theor. Appl. Genet, 89: 442-450

Koller B, Lehmann, A.., T. M. M. Dermott, T.M.M., Gessler,C. 1993. Identification of apple cultivars using RAPDs and RLFPs, Agronomy, 17: 323-333

Lewis, E.1992. Identification of avocado cultivars with RAPD markers. Inligtings bulletinInstituat Vir Tropiese en Subtropese Gewasse No. 241: 7-9

Metais, I., Aubry, C., .Hamon, B and Jalouzot, R. 2000. Description and Analysis of Genetic Diversity between Commercial Bean Lines (Phaseolus vulgaris L.) Theoretical and Applied Genetics, 101(8): 1207-1214 
Prakash D.P, Narayanaswamy, P.,Sondur, S. N. 2003. Analysis of molecular diversity in guava using RAPD markers. Journal of Horticultural Science and Biotechnology, 77: 287-293

Purseglove, J.W. 1987. Tropical crops. Dicotyledons, Longria, Science and Technology, pp 204-206

Purseglove J.. Brown, W.E.G., Green, C.L and Robbins, S.R.J 1981 Tamarind. In: Spices, Longman Group, New York, 1: 210

Ravishankar K.,. Anand, V.L and Dinesh. M.R, 2000 Assessment of genetic relatedness among mango cultivars of India using RAPD markers. Journal of Horticultural Science and Biotechnology, 75:198-201

Rokhade A.K, .Nalvwadi, U.G and.Faroogui, A.A 1989. Evaluation of promising hybrids in sapota (Manilkara archas (Mill) Fosberg) at Dharwad. I. Fruit characters. Karnataka Journal of Agricultural Sciences, 2:286-290

Schnell, R. J.,Brown, J.S., Olano, C.T and Meerow, A.W. 2006. Mango genetic diversity analysis and pedigree inferences for florida cultivars using microsatellite marker. Journal of American Society, 131 (2): 214 - 224

Shah F. H., Rashid, O., Simons, A.J and Dusdon, A. 1994 The utility of RAPD markers for determination of genetic variation in oil palm (Elaeis guineensis). Theory Applied Genetics, 89: 713-718

Shimida T, Hayama, Haji, T., Yamaguchi, M and Yoshida, M. 1999 Genetic diversity of plums characterized by RAPD analysis. Euphytica, 109: 143-147

Sokal R.R and Sneath, P.H.A. 1973. Principles of Numerical Taxonomy. W.H. Freeman and Co., San Francisco, USA

Ward J.H. 1963. Hierarchic grouping to optimize an objective function. Journal of American Statistical Association, 58: 236-239

Williams J.G., Kubelik., J.A., Livak., A.R., Raflaski., K.J and . Tingey, S.V. 1990. DNA polymorphisms amplified by arbitrary primers are useful as genetic markers. Nucleic Acids Research 18:6531-6535 
Table 1. Tamarind cultivars used in this study

\begin{tabular}{c|l|l|l}
\hline S. No. & Flowering cultivars & S.No & \multicolumn{1}{c}{ Non- flowering accessions } \\
\hline 1. & PKM 1 & 5. & Tamarindus indica-9 \\
2. & Red tamarind & 6. & Tamarindus indica-2 \\
3. & Sweet tamarind & 7. & Tamarindus indica-1 \\
4. & Urigam & 8. & Tamarindus indica-7 \\
& & 9. & Tamarindus indica-3 \\
\hline
\end{tabular}

Table 2. Details of bands generated by RAPD primers

\begin{tabular}{l|l|c}
\hline Primer used & Primer sequence & $\begin{array}{c}\text { Number of } \\
\text { polymorphic bands }\end{array}$ \\
\hline OPA-A09 & GGGTAACGCC & 7 \\
OPA-B06 & TGCTCTGCCC & 8 \\
OPA-K06 & CACCTTTCCC & 7 \\
OPA-R15 & GGACAACGAG & 12 \\
OPA-X01 & CTGGCATCTC & 8 \\
OPA-Y01 & GTGGCATCTC & 9 \\
OPG-05 & CTGAGACGGA & 2 \\
OPG-09 & CTGACGTCAC & 2 \\
OPG-13 & CTCTCCGCCA & 1 \\
OPG-19 & GTCAGGGCAA & 2 \\
& Totals & 58 \\
& Average & 5.8 \\
\hline
\end{tabular}




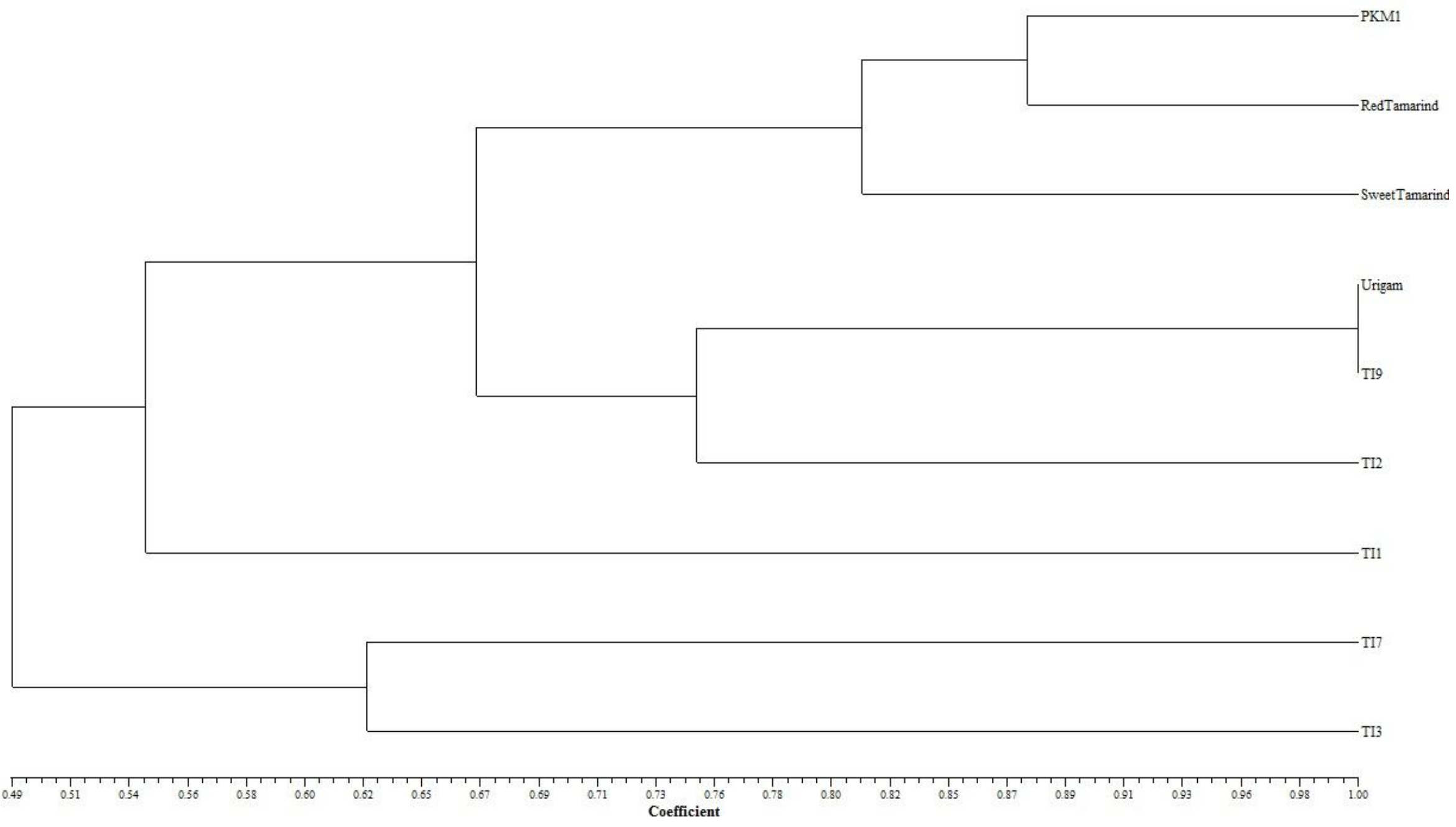

Figure 1. Phenogram of nine tamarind cultivars based on RAPD data. The phylogenetic tree obtained from Unweighted Pair-Group (UPGMA) cluster method of Nei's genetic distances option in the NTSYS-PC1.2 program 


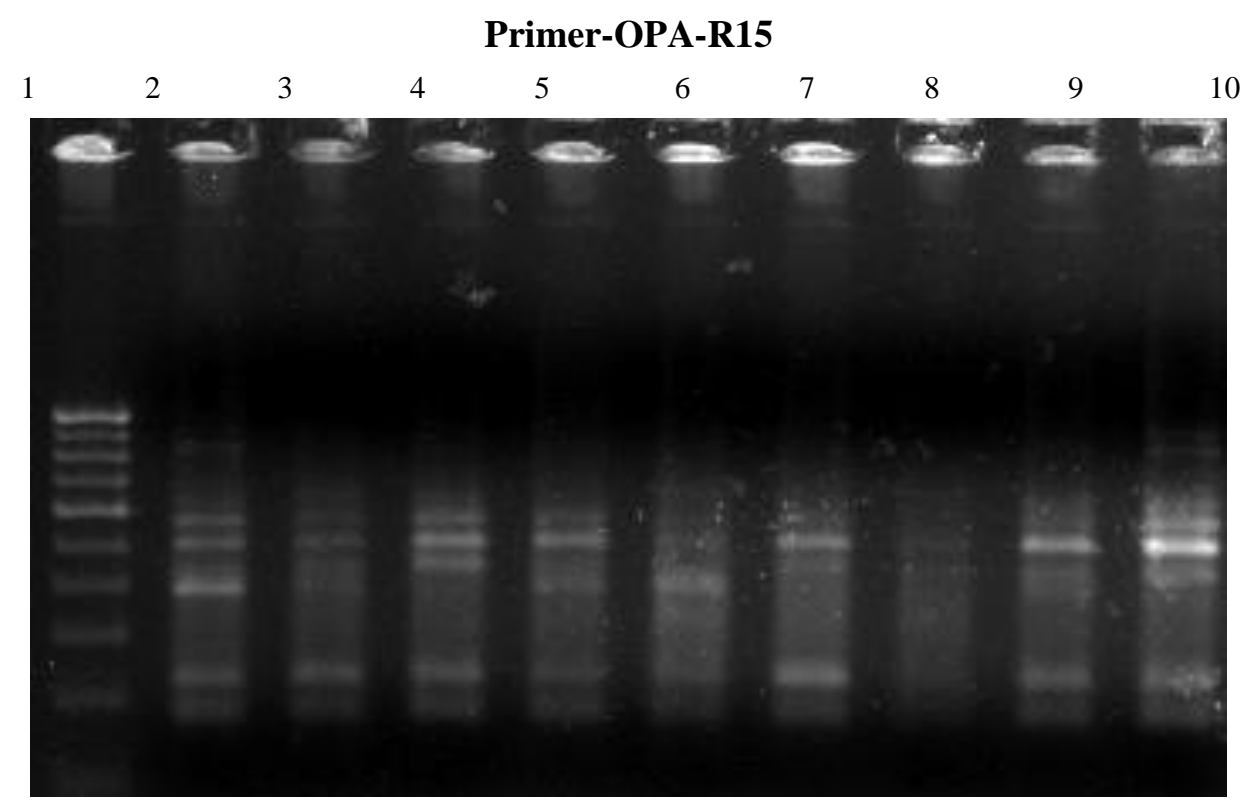

1-100 BP Ladder, 2-PKM1, 3-Red tamarind, 4- Sweet tamarind, 5-Urigam, 6-Tamarindus indica 9,7Tamarinds indica 2, 8-Tamarindus indica 1, 9-Tamarindus indica 7, 10-Tamarindus indica 3

\section{Primer-OPA-B06}

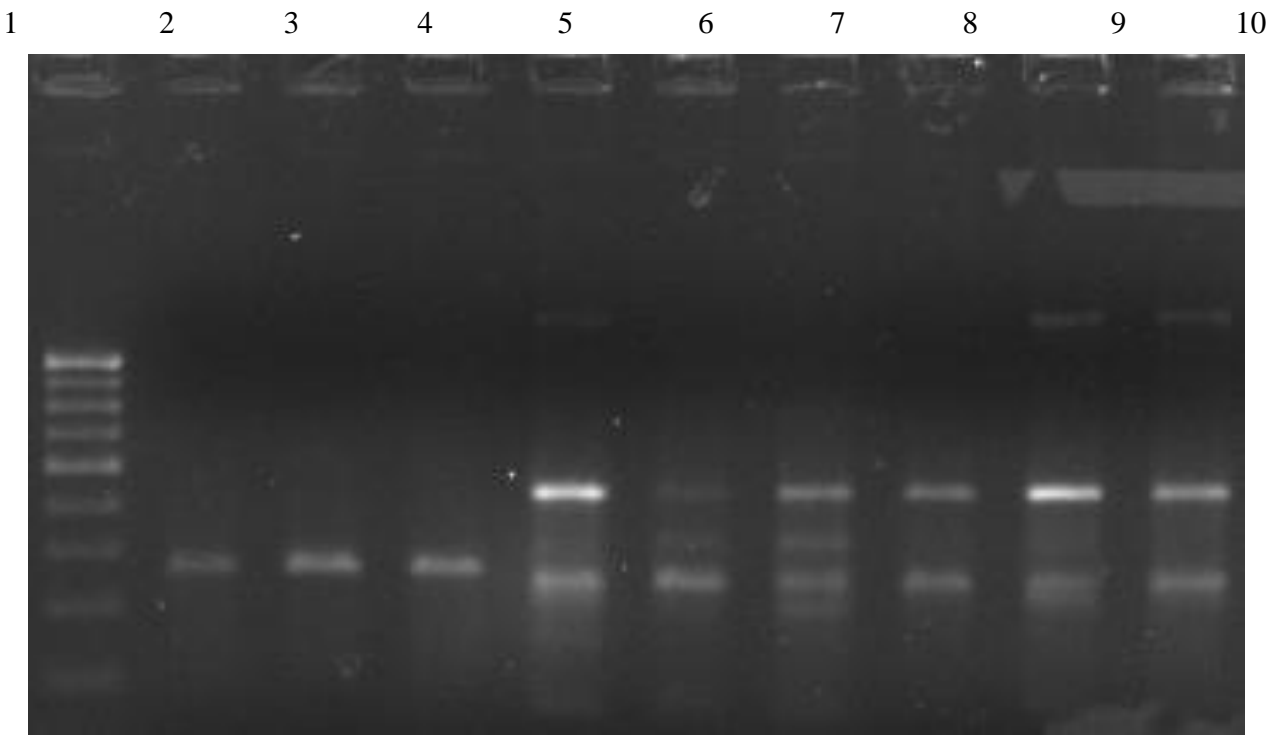

1-100 BP Ladder, 2-PKM1, 3-Red tamarind, 4- Sweet tamarind, 5-Urigam, 6-Tamarindus indica 9,7Tamarinds indica 2, 8-Tamarindus indica 1, 9-Tamarindus indica 7, 10-Tamarindus indica 3

Figure 2. Random Amplified Polimoriphic DNA (RAPD) profiles of nine different tamarind cultivars 